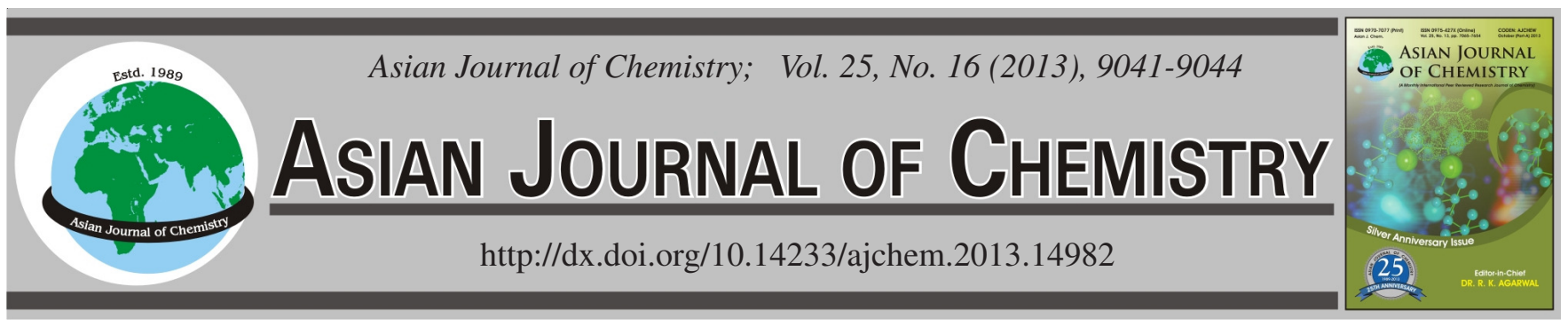

\title{
Determination of Trace Copper in Drinking Water by Flame Atomic Absorption Spectrometry After Solid Phase Extraction on Polymer Modified Silica Gel
}

\author{
Jing Chen", Ning Wang, Bo Li, Donguin Wan and XuZhuo Sun
}

School of Chemistry and Chemical Engineering, Henan University of Technology, Zhengzhou City 450001, P.R. China

*Corresponding author: Fax: +86 371 67756718; Tel: +86 18637192696; E-mail: chj-chs@163.com

\begin{abstract}
Silica gel was chemically modified by a polymer containing thiol group and used as a solid phase extraction adsorbent for the determination of trace copper in drinking water samples by flame absorption spectrometry. The effects of $\mathrm{pH}$, sample flow rate and volume, elution conditions and concomitant ions on the recovery of the analyte were investigated. The results showed that copper could be adsorbed at $\mathrm{pH}$ 6 and eluted by $4 \mathrm{~mL} \mathrm{HCl}$ solution $\left(0.5 \mathrm{~mol} \mathrm{~L}^{-1}\right)$. Under the optimized conditions, the adsorption capacity of modified silica gel was found to be $3.7 \mathrm{mg} \mathrm{g}^{-1}$ for copper. The detection limit of the proposed method was $1.3 \mathrm{ng} \mathrm{mL}^{-1}$ for copper with an enrichment factor of 18.7 . The analytical result for the certified reference water sample(GBWE080081) was in a good agreement with the certified value. The proposed method has also been successfully applied to the determination of trace copper in boiled water, purified water and mineral water with the recoveries for spiked samples between 96 and $103 \%$.
\end{abstract}

Key Words: Silica gel, Solid phase extraction, Copper, Drinking water, Flame absorption spectrometry.

\section{INTRODUCTION}

Copper is an essential element for human body and it plays an important role in carbohydrate and lipid metabolism. It has many biological effects as an essential element as well as a toxic one ${ }^{1}$. In general, a daily copper intake of $1.5-2.0 \mathrm{mg}$ is essential for adults and copper at nearly $40 \mathrm{ng} \mathrm{mL}^{-1}$ is required for normal metabolism of many living organisms ${ }^{1,2}$. But, copper at higher levels is toxic and severe oral intoxication mainly affect the blood and kidneys. Because of these, the European Commission has fixed the limit of $2 \mu \mathrm{g} \mathrm{mL} \mathrm{m}^{-1}$ for copper in drinking water and the allowed limit of copper is set to $1.3 \mu \mathrm{g} \mathrm{mL}^{-1}$ in the USA similar to that in Canada and China $\left(1.0 \mu \mathrm{g} \mathrm{mL}^{-1}\right)^{3,4}$. Therefore, it is important for monitoring trace copper in drinking water. It is necessary to develop sensitive, simple, rapid methods for the quality evaluation and control of drinking water.

Compared with other elemental detectors, FAAS has the characteristics of good precision, simple operation and lower cost. However, it is difficult for the direct determination of metals at trace level in complicated samples by FAAS for its insufficient sensitivity and matrix effect ${ }^{5}$. To solve this problem, sample pretreatment procedure prior to determination by FAAS is a popular choice. Preconcentration is a very important issue for improvement of sensitivity and separation which is an efficient technique to reduce the interference of sample matrix ${ }^{6}$.
Various sample pretreatment procedures have been used for this purpose, including liquid-liquid extraction ${ }^{7}$, solid phase extraction $^{8,9}$, ion exchange technique ${ }^{10}$, coprecipitation $^{11}$ and cloud point extraction ${ }^{12,13}$.

Recently, solid phase extraction(SPE) technique has become increasingly popular for the enrichment of metal ions prior to their determination. Compared with conventional liquid-liquid extraction methods, SPE technique has the following advantages, i.e., high preconcentration factor, simple operation, rapid phase separation, reduced operation time and cost and convenient combination with different detection techniques ${ }^{6,14}$.

It is well known that the adsorption medium plays a key role in improving the analytical performance of SPE and much attention has been paid to the investigation of new materials by SPE in recent years ${ }^{15}$. Among wide range of solid adsorbents, such as chelating resins, silica gel, carbon sorbents, inorganic based sorbents, biological adsorption material and nanomaterials ${ }^{6,15-18}$, silica gel bonded chelating ligands has gained much more attention for metal ion enrichment for its definite advantages, such as good mechanical strength, no swelling and straining, good thermal stability and convenient chemical modification $^{19}$.

In this paper, silica gel was modified with a polymer containing thiol group and the obtained adsorbent was used for the enrichment of trace copper in drinking water samples. 
The SPE preconcentration procedure was combined with FAAS for the determination of trace copper in different drinking water samples.

\section{EXPERIMENTAL}

TAS-986 atomic absorption spectrometry (Beijing purkinjen general instrument Co., Ltd., Beijing, China.) with silver hollow cathode lamps (KY-1) was used for the determination. The instrumental parameters used were those recommended by the manufacture. The $\mathrm{pH}$ values were controlled with a PHS-3C pH-meter (Shanghai precision \& scientific instrument Co., Ltd., Shanghai, China). A HL-2D constant flow pump (Shanghai Qingpu Huxi Instrument Factory, Shanghai, China) and a selfmade poly-tetrafluoroethylene (PTFE) micro-column (30 mm $\times 4.0 \mathrm{~mm}$, i.d.) packed with polymer modified silica gel was used in the solid phase extraction process.

Standard solutions and reagents: All reagents used were analytical-reagent grade. Amino bonded silica gel (average diameter 45-75 $\mu \mathrm{m}$, Fuji Chromatorex) and polyisobutylenealt-maleic anhydride (Mw 6000) were purchased from sigmaaldrich. L-Cysteine and N,N-dimethyl formamide (AR, Shanghai Huixing Biochemical Reagent Company, Shanghai, China) were used for reaction directly. The stock standard solutions $\left(1 \mathrm{~g} \mathrm{~L}^{-1}\right)$ of copper was prepared by dissolving appropriate amounts of copper nitrate (Sinopharm Chemical Reagent Co., Ltd, Shanghai, China) in deionized water. $\mathrm{HCl}$ (pH 1.0-2.0), acetate-acetic acid buffer ( $\mathrm{pH} 3.0-5.0)$ and $\mathrm{NaOH}$ solution $(0.1$ mol L ${ }^{-1}$ ) were used for $\mathrm{pH}$ adjustment. Different stock solutions of potentially interfering ions $\left(1.000 \mathrm{~g} \mathrm{~L}^{-1}\right)$ were prepared according to the conventional method. Working solutions were prepared daily by appropriate dilutions of stock solutions in brown flask. The laboratory glassware was kept in a $5 \%(\mathrm{v} / \mathrm{v})$ nitric acid solution overnight. Afterwards, it was rinsed thoroughly with deionized water and dried.

Preparation of the adsorbent: The preparation of the polymer modified silica gel was illustrated in Fig. 1. Firstly, polyisobutylene-alt-maleic anhydride $(2.5 \mathrm{~g})$ and L-cysteine $(1.5 \mathrm{~g})$ was dissolved in DMF $(250 \mathrm{~mL})$, then refluxed at $130{ }^{\circ} \mathrm{C}$ for $1 \mathrm{~h}$ with magnetic stirring. After refluxing, the reactant was cooled to room temperature and the amino-bonded silica gel $(1.5 \mathrm{~g})$ was added and refluxed at $130{ }^{\circ} \mathrm{C}$ for $1.5 \mathrm{~h}$ with magnetic stirring. After cooled to room temperature, the resultant product was collected through decompress filter. The obtained particles was washed with methanol $(100 \mathrm{~mL})$ and deionized water $(100 \mathrm{~mL})$ and dried in vaccum.

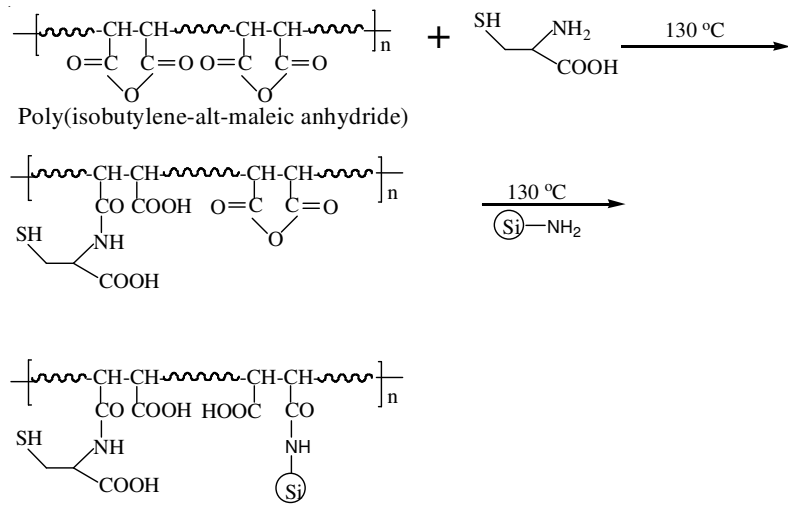

Fig. 1. Synthesis of polymer modified silica gel adsorbent
Preparation of micro-column: A total of $70 \mathrm{mg}$ of polymer modified silica gel was filled into a PTFE micro-column (30 $\mathrm{mm} \times 4.0 \mathrm{~mm}$, i.d.) plugged with a small portion of adsorbent cotton at both ends. Before use, deionized water was passed through the column in order to clean it.

Procedure of column experiments: In the column experiments, a $100.0 \mathrm{~mL}$ sample or standard solution containing silver was adjusted to $\mathrm{pH} 6.0$ and was passed through the column by using a peristaltic pump at $4.0 \mathrm{~mL} \mathrm{~min}^{-1}$ of sample flow rate. Afterwards, copper retained on the column was eluted with $4.0 \mathrm{~mL} \mathrm{HCl}$ solution $\left(0.5 \mathrm{~mol} \mathrm{~L}^{-1}\right)$ at elution flow rate of $1.0 \mathrm{~mL} \mathrm{~min}^{-1}$. Finally, the analyte in the effluents was determined by FAAS.

Sample preparation: The boiled water, purified water and mineral water were collected in the local supermarket and campus (Henan University of Technology ). Then several drops of $\mathrm{HNO}_{3}\left(0.5 \mathrm{~mol} \mathrm{~L}{ }^{-1}\right)$ were added into the water samples. After filtration, the water was passed through $0.45 \mu \mathrm{m}$ filtration membrane, the obtained water was used for determination.

\section{RESULTS AND DISCUSSION}

Characterization of polymer modified silica gel: The elemental analysis results for the polymer modified silica gel was as follow: N $13.9 \%$ (wt), C $42.5 \%$ (wt), H $7.7 \%$ (wt), S $5.1 \%(w t)$. And the amount of thiol group on the surface of adsorbent was determined according to the Ellman method ${ }^{20}$. It was found that the amount of thiol group on the adsorbent was $0.29 \mathrm{mmol} \mathrm{g}^{-1}$. The above details clearly demonstrated the successful modification of silica gel with polymer containing thiol group.

Effect of pH: $\mathrm{pH}$ value plays a key role in the SPE procedure. An appropriate $\mathrm{pH}$ value can not only improve the adsorption efficiency, but also depress the interference of sample matrix. The adsorption behaviour of copper on polymer modified silica gel was studied according to the procedure of column experiments. The effect of $\mathrm{pH}$ on the adsorption ( $\mathrm{R}$ $\%$ ) of copper on polymer modified silica gel was showed in Fig. 2. It can be seen that silver was adsorbed quantitatively (R larger than $90 \%$ ) on polymer modified silica gel within a $\mathrm{pH}$ range of 4-7. For further experiments, $\mathrm{pH} 6.0$ was chosen for preconcentration of copper.

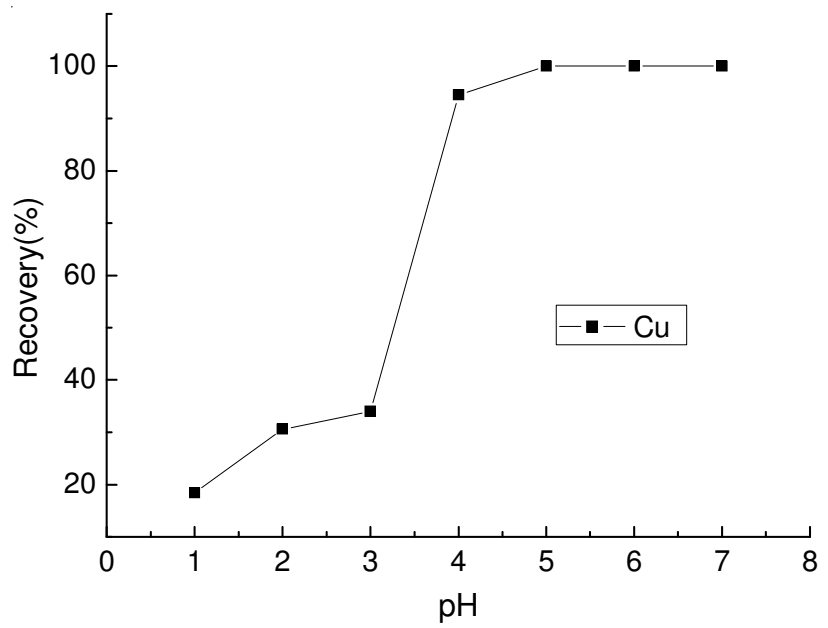

Fig. 2. Effect of $\mathrm{pH}$ on the adsorption ( $\mathrm{R} \%)$ of copper on polymer modified silica gel 
Optimization of elution conditions: It is obvious from Fig. 2 that the adsorptions of copper decrease sharply with the decrease of $\mathrm{pH}$ value. For this reason, various concentrations (0.5-2.0 $\left.\mathrm{mol} \mathrm{L}^{-1}\right)$ of $\mathrm{HCl}$ were studied for the elution of retained analytes at $0.5 \mathrm{~mL} \mathrm{~min}^{-1}$ of elution flow rate. The results showed that quantitative recoveries $(>90 \%)$ could be obtained in the tested $\mathrm{HCl}$ concentration range. Then $\mathrm{HCl}\left(0.5 \mathrm{~mol} \mathrm{~L}^{-1}\right)$ was used as eluent.

The elution volume and elution flow rate could affect the elution efficiency remarkably. By using $\mathrm{HCl}\left(0.5 \mathrm{~mol} \mathrm{~L}^{-1}\right)$ solution as the eluent, the effect of elution volume on the quantitatively elution of analytes was investigated according to the procedure of column experiments. $5.0 \mathrm{~mL}$ of eluent was used to elute the analytes on the polymer modified silica gel, the eluent was collected at $0.5 \mathrm{~mL}$ intervals. Fig. 3 showed the recovery of analytes in each portion determined by FAAS. As can be seen, the recovery of analytes was larger than $95 \%$ when eluent volume larger than $3.0 \mathrm{~mL}$. That means quantitatively elution could be obtained when elution volume higher than $3.0 \mathrm{~mL}$ for silver. And it was also found that quantitatively elution could be obtained with elution flow rate no more than $1.0 \mathrm{~mL} \mathrm{~min}^{-1}$. Thus, the elution conditions used in the following experiments were as follow: the $\mathrm{HCl}\left(0.5 \mathrm{~mol} \mathrm{~L}^{-1}\right)$ solution elution volume was $4.0 \mathrm{~mL}$ and the elution flow rate was 1.0 $\mathrm{mL} \min ^{-1}$.

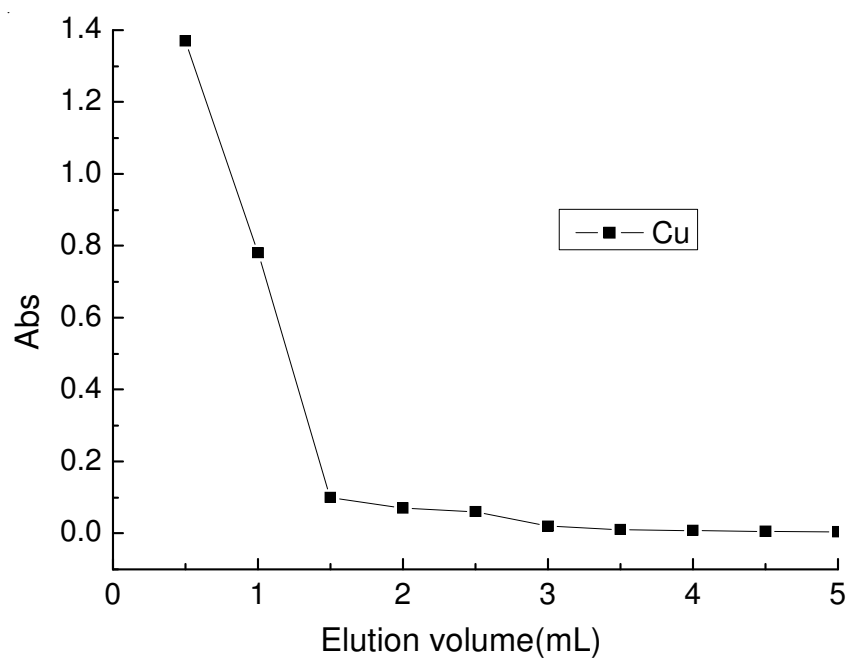

Fig. 3. Effect of eluent volume on the recovery of copper

Effect of sample flow rate and sample volume: The sample flow rate should be optimized to ensure quantitatively retention along with minimization of the time required for sample processing. It was found that the flow rate in the range of $0.5-4.0 \mathrm{~mL} \mathrm{~min}^{-1}$ had no significant effect on the recoveries of copper according to the procedure of column experiments. For further experiments, $4.0 \mathrm{~mL} \mathrm{~min}^{-1}$ was chosen as the sample flow rate.

In order to obtain a high or achievable preconcentration factor of very dilute analyte solutions from large volumes, it is imperative to investigate the effect of sample volume on the retention of analytes on the modified silica gel. It was found that quantitative recovery for copper was obtained when sample volumes were less than $100 \mathrm{~mL}$. So a theoretical enrichment factor of 25 can be achieved by this method.
Effect of concomitant: The effect of potential co-existing ions on the preconcentration and determination of the studied analyte was investigated. In this experiment, the copper standard solution $\left(20 \mathrm{ng} \mathrm{mL}^{-1}\right)$ containing the added interfering ions were treated according to the procedure of column experiments. The content of copper in the eluent was determined in order to calculate the recovery of analyte. The tolerances of the co-existing ions, defined as the maximum concentration of co-existing ion that could achieve $>90 \%$ recovery of copper were given in Table-1. It could be seen that the presence of major cations had no obvious influence on the target element adsorption under the selected conditions except for $\mathrm{Hg}^{2+}$. The could be explained by the fact the chelation capability of thiol group for $\mathrm{Hg}^{2+}$ is much greater than that for $\mathrm{Cu}^{2+}$.

\begin{tabular}{ccc}
\multicolumn{3}{c}{ TABLE-1 } \\
TOLERANCE LIMITS OF CO-EXISTING IONS \\
\hline Substance & Maximum tolerable amount $\left(\mu \mathrm{gL}^{-1}\right)$ & Recovery $(\%)$ \\
\hline $\mathrm{Na}^{+}$ & 400 & 103.5 \\
$\mathrm{~K}^{+}$ & 600 & 97.9 \\
$\mathrm{Ca}^{2+}$ & 600 & 101.4 \\
$\mathrm{Mg}^{2+}$ & 400 & 105.0 \\
$\mathrm{Zn}^{2+}$ & 5.0 & 94.5 \\
$\mathrm{~Pb}^{2+}$ & 2.0 & 101.6 \\
$\mathrm{Cd}^{2+}$ & 2.0 & 100.0 \\
$\mathrm{Ni}^{2+}$ & 4.0 & 92.6 \\
$\mathrm{Hg}^{2+}$ & 0.01 & 94.5 \\
$\mathrm{Co}^{2+}$ & 4.0 & 100.2 \\
\hline
\end{tabular}

Column regenerability and adsorption capacity: The regenerability and stability of adsorbent was investigated by passing the copper standard solution $\left(100 \mathrm{~mL}, 20 \mathrm{ng} \mathrm{mL}^{-1}\right)$ and then passing $4 \mathrm{~mL}$ of $\mathrm{HCl}\left(0.5 \mathrm{~mol} \mathrm{~L}^{-1}\right)$ solution and 10 $\mathrm{mL}$ of deionized water through the column packed with 70 mg of polymer modified silica gel. It was observed that the column could be reused up to 40 runs with the recoveries of the target ion larger than $90 \%$.

The adsorption capacity of polymer modified silica gel was studied in order to evaluate the amount of adsorbent required to quantitatively concentrate the analyte from a given solution. The method used was adapted from the recommended procedure by Maquieira et al. ${ }^{21}$. The adsorption capacities of copper was $3.7 \mathrm{mg} \mathrm{g}^{-1}$.

Analytical performance: Under the optimized experiment conditions, the analytical performance of the method was evaluated. Based on the definition of IUPAC, the detection limits $(3 \sigma)$ of this method was $1.3 \mathrm{ng} \mathrm{mL}^{-1}$ for copper, the relative standard deviation (RSD) were $2.9 \%\left(\mathrm{c}=20 \mathrm{ng} \mathrm{mL}^{-1}\right.$, $\mathrm{n}=7)$. The calibration graph for the preconcentration procedure was $\mathrm{A}=0.0029 \mathrm{C}+0.017(\mathrm{R}=0.997)$ for $5-50 \mathrm{ng} \mathrm{mL} \mathrm{m}^{-1}$ and the calibration graph without preconcentration was $\mathrm{A}=$ $0.000155 \mathrm{C}-0.0305(\mathrm{R}=0.997)$. The enrichment factor $(\mathrm{EF}$, calculated as the ratio of the slopes of the calibration graphs with preconcentration and direct aspiration, respectively) was 18.7.

Sample analysis: For real sample analysis, the standard calibration curve method was employed. In order to evaluate the validity of the procedure, the method has been applied to the determination of copper in the certified reference sample 
(GBWE080081 water sample). The analytical results showed a good agreement between the determined values $(0.491 \pm$ $\left.0.008 \mu \mathrm{g} \mathrm{mL}^{-1}\right)$ and the certified values $(0.5000 \pm 0.013 \mathrm{mg}$ $\left.\mathrm{mL}^{-1}\right)$.

The proposed method was also applied to the determination of trace copper in different drinking water samples(boiled water, purified water and mineral water). The analytical results and the recoveries for the spiked samples were given in Table-2. It could be seen that the recoveries for the spiked samples is between 96 and $103 \%$.

\begin{tabular}{cccc}
\hline \multicolumn{4}{c}{ TABLE-2 } \\
ANALYTICAL RESULTS FOR COPPER IN \\
DRINKING WATER SAMPLES (MEAN \pm SD, $\mathrm{n}=3$ ) \\
\hline Sample (ng mL ${ }^{-1}$ ) & Added & Found & Recovery $(\%)$ \\
\hline \multirow{3}{*}{ Boiled water } & 0 & $6.8 \pm 0.2$ & - \\
& 10 & $17.1 \pm 0.6$ & 103 \\
& 20 & $27.2 \pm 0.8$ & 102 \\
\hline \multirow{3}{*}{ Purified water } & 0 & - & - \\
& 10 & $9.6 \pm 0.2$ & 96 \\
& 20 & $20.2 \pm 0.6$ & 101 \\
\hline \multirow{3}{*}{ Mineral water } & 0 & $12.2 \pm 0.3$ & - \\
& 10 & $22.4 \pm 0.6$ & 102 \\
& 20 & $31.6 \pm 0.9$ & 97 \\
\hline
\end{tabular}

\section{Conclusion}

A simple, rapid and reliable method was developed for the preconcentration and FAAS determination of trace copper in drinking water samples by using polymer modified silica gel as micro-column packing material. The adsorption behaviour of copper on the modified silica gel had been systematically studied. It was found that the polymer modified silica gel showed a high adsorption capacity for copper and the analyte retained on its surface can be easily desorbed. Hence, polymer modified silica gel showed great potential as an adsorbent for the preconcentration of trace metal ions in samples with complicated matrix.

\section{ACKNOWLEDGEMENTS}

This research was financially supported by the National Science Foundation of China (51102079, 21101057).

\section{REFERENCES}

1. E. Kendüzler and A.R. Türker, Anal. Chim. Acta, 480, 259 (2003).

2. A.R. Ghiasvand, R. Ghaderi and A. Kakanejadifard, Talanta, 62, 287 (2004).

3. P. Rumori and V. Cerdà, Anal. Chim. Acta, 486, 227 (2003).

4. Z. Szigeti, I. Bitter, K. Toth, C. Latkoczy, D.J. Fliegel, D. Gunther and E. Pretsch, Anal. Chim. Acta., 532, 129 (2005).

5. Y. Wang, M.L. Chen and J.H. Wang, Appl. Spectrosc. Rev., 42, 103 (2007).

6. V.S. Camel, Spectrochim. Acta B, 58, 1177 (2003).

7. D. Barkat And M. Omari, Asian J. Chem., 17, 202 (2005).

8. N. Garcia-Otero, C. Teijeiro-Valino, J. Otero-Romani, E. Pena-Vázquez, A. Moreda-Pineiro and P. Bermejo-Barrera, Anal. Biochem. Chem., 395, 1107 (2009).

9. C. Puls and A. Limbeck, Anal. At. Spectrom., 24, 1434 (2009).

10. J. Dumont, M. Cote and J. Hubert, Appl. Spectrosc., 43, 1132 (1989).

11. U. Divrikli and L. Elci, Anal. Chim. Acta, 452, 231 (2002).

12. J.A. Baig, T.G. Kazi, A.Q. Shah, M.B. Arain, H.I. Afridi, G.A. Kandhro and S. Khan, Anal. Chim. Acta, 65, 157 (2009).

13. X.D. Wen, P. Wu, L. Chen and X.D. Hou, Anal. Chim. Acta, 650, 33 (2009).

14. A.R. Turker, Sep. Purif. Rev., 41, 169 (2012).

15. A.R. Turker, Clean: Soil, Air, Water., 35, 548 (2007)

16. V.A. Lemos, L.S.G. Teixeira, M.D. Bezerra, A.C.S. Costa, J.T. Castro, L.A.M. Cardoso, D.S. de Jesus, E.S. Santos, P.X. Baliza and L.N. Santosi, Appl. Spectrosc. Rev., 43, 303 (2008).

17. A. Safavi, N. Iranpoor and N. Saghir, Sep. Purif. Technol., 40, 303 (2004).

18. M. Savio, B. Parodi, L.D. Martinez, P. Smichowski and R.A. Gil, Talanta, 85, 245 (2011).

19. A.R. Sarkar, P.K. Datta and M. Sarkar, Talanta, 43, 1857 (1996).

20. G.L. Ellman, Arch. Biochem. Biophys., 82, 70 (1959).

21. A. Maquieira, H.A.M. Elmahadi and R. Puchades, Anal. Chem., 66, 3632 (1996). 